\title{
Erratum to: Intraluminal measurement of papillary duct urine pH, in vivo: a pilot study in the swine kidney
}

\author{
Rajash K. Handa ${ }^{1} \cdot$ James E. Lingeman $^{2} \cdot$ Sharon B. Bledsoe $^{1}$. \\ Andrew P. Evan ${ }^{1} \cdot$ Bret A. Connors $^{1} \cdot$ Cynthia D. Johnson ${ }^{1}$
}

Published online: 5 March 2016

(C) Springer-Verlag Berlin Heidelberg 2016

\section{Erratum to: Urolithiasis}

\section{DOI 10.1007/s00240-015-0834-9}

The original version of this article unfortunately contained a mistake. The affiliation of Rajash K. Handa and James E. Lingeman are incorrect. The correct affiliation should be:

Rajash K. Handa

Department of Anatomy and Cell Biology, Indiana University School of Medicine, Indianapolis, IN, USA

James E. Lingeman

Department of Urology, Indiana University Health at Methodist Hospital, Indianapolis, IN, USA

The online version of the original article can be found under doi:10.1007/s00240-015-0834-9.

Rajash K. Handa

rajash_handa@hotmail.com

1 Department of Anatomy and Cell Biology, Indiana University School of Medicine, Indianapolis, IN, USA

2 Department of Urology, Indiana University Health at Methodist Hospital, Indianapolis, IN, USA 